\title{
Erbium,Chromium:Yttrium-Scandium-Gallium-Garnet Laser-assisted Excision of Peripheral Giant Cell Granuloma
}

\author{
${ }^{1}$ Murali Tuppili, ${ }^{2}$ Butchi Babu, ${ }^{3}$ Uday Kiran Uppada, ${ }^{4}$ Sushma Naagmega, ${ }^{5}$ Ramesh Amirisetty
}

\begin{abstract}
Peripheral giant cell granuloma (PGCG) is a benign reactive softtissue lesion of the anterior mandible. It is a common giant cell lesion of the oral cavity whose histogenesis still continues to be a topic of debate. Clinically, the lesion is soft in consistency generally not measuring more than $2 \mathrm{~cm}$ and rarely causes bone or root resorption unlike central giant cell granuloma (CGCG). The treatment is usually local surgical excision down to underlying bone along with removal of any existing etiological factor to minimize risk of recurrence. Existing literature is sparse on the pros and cons of the use of a surgical laser in the management of such giant cell lesions. With the advent of new technology, lasers have taken the sheen away from scalpel. We preferred the erbium,chromium:yttrium-scandium-galliumgarnet (Er,Cr:YSGG) laser with a wavelength of $2780 \mathrm{~nm}$ which is well absorbed by water, hence minimizing any thermal damage to the soft tissues. Probably, this case report might be a first of its kind highlighting the use of an Er,Cr:YSGG laser for the excision of PGCG. Hence, this article is intended to highlight the clinical presentation and differential diagnosis of PGCG with special emphasis on the beneficial aspects of managing such lesions with Er,Cr:YSGG laser.
\end{abstract}

Keywords: Er,Cr:YSGG laser, Peripheral giant cell granuloma, Hyperplastic gingival lesion.

How to cite this article: Tuppili M, Babu B, Uppada UK, Naagmega S, Amirisetty R. Erbium,Chromium:Yttrium-ScandiumGallium-Garnet Laser-assisted Excision of Peripheral Giant Cell Granuloma. Int J Laser Dent 2014;4(2):54-58.

\section{Source of support: Nil}

Conflict of interest: None

\footnotetext{
${ }^{1-3}$ Consultant, ${ }^{4,5}$ Reader

1,2Department of Periodontics, FMS Dental Hospital, Hyderabad, Telangana, India

${ }^{3}$ Department of Oral and Maxillofacial Surgery, FMS Dental Hospital, Hyderabad, Telangana, India

${ }^{4}$ Department of Oral Pathology, Meghna Institute of Dental Sciences, Hyderabad, Telangana, India

${ }^{5}$ Department of Periodontics, Chhattisgarh Dental College and Research Institute, Rajnandgaon, Chhattisgarh, India
}

Corresponding Author: Butchi Babu, Consultant, Department of Periodontics, FMS Dental Hospital, Hyderabad, Telangana India, Phone: 04098779863, e-mail: docbutchi@gmail.com

\section{INTRODUCTION}

Peripheral giant cell granuloma (PGCG) is a rare reactive, soft-tissue exophytic mass occurring within the oral cavity. ${ }^{1}$ Giant cell epulis, osteoclastoma, peripheral giant cell reparative granuloma or giant cell hyperplasia are frequently used synonyms for this peculiar lesion. ${ }^{2,3}$ It accounts for $7 \%$ of all benign tumors of the jaw. ${ }^{4}$ Literature over the years reveal PGCG as a reactive lesion caused by local irritation like calculus, bacterial plaque or trauma from rough and overhanging restoration margins, chronic infections and food impaction. ${ }^{1-3,5,6}$ PGCG seems to be influenced by hormonal stimulus, especially estrogen reflecting the high female predilection of this lesion. ${ }^{4}$ However, low socioeconomic status of the patients and unfavorable oral hygiene seems to be predisposing factors. ${ }^{3,6}$

Generally, PGCG is asymptomatic, but occasionally patients complain of bleeding and pain. ${ }^{7}$ It occurs commonly in the mandibular arch with affinity toward the region anterior to the permanent first molar. ${ }^{5}$ It occurs exclusively on gingiva or edentulous alveolar ridge as variable sized, sessile or pedunculated lesion which is usually deep red to bluish red with high bleeding tendency. ${ }^{1,3,5}$

Clinically, it rarely exceeds $2 \mathrm{~cm}$ in diameter and generally soft or rubbery in consistency which rarely causes bone or root resorption unlike central giant cell granuloma (CGCG). ${ }^{8}$ The treatment is usually local surgical excision down to underlying bone along with removal of any existing etiological fact or to minimize risk of recurrence. ${ }^{1,2}$ We present a case of a small pedunculated, firm nodular growth in the lower anterior mandible which was clinically and radiologically diagnosed as a hyperplastic gingival lesion and was confirmed histopathologically as PGCG.

\section{CASE REPORT}

A 45-year-old male patient reported to our dental hospital with the chief complaint of a painless growth in relation to the gingiva of the lower anterior region that interfered with his function and esthetics for the past 6 months. On clinical examination, there was a growth in the lower 


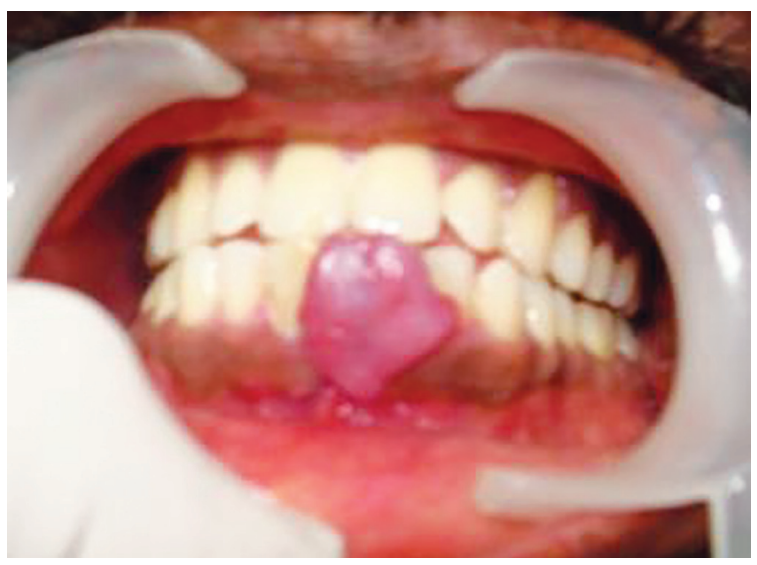

Fig. 1: Preoperative view showing the lesion

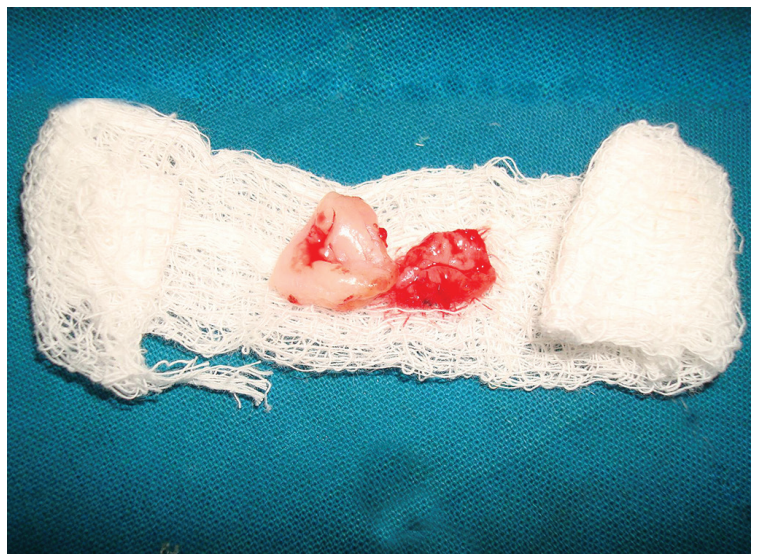

Fig. 3: Excised lesion

anterior region. History revealed that the growth started initially as a small lesion in the interdental papilla region between lower central incisor teeth and slowly grew in size to attain the current size. It was a pedunculated pale pink-colored growth exhibiting well-defined margins, measuring approximately $3 \times 2 \mathrm{~cm}$ mediolateral and occlusogingivally which was nontender and firm in consistency that slightly bleeds on probing (Fig. 1). History suggested that the patient was in good health without any associated comorbid conditions.

A radiograph of the lower anterior region revealed slight crestal resorption of the interdental bone between both the lower central incisors (Fig. 2). Based on the history, clinical and radiological examination, we arrived at a provisional diagnosis of pyogenic granuloma keeping our options open to peripheral ossifying fibroma, papilloma, peripheral odontogenic fibroma and PGCG as our differential diagnosis.

The patient was subjected to thorough medical evaluation and hematological investigations followed by proper phase one periodontal therapy. Later, the patient was taken up for a laser-assisted surgical excision of the lesion. Before the procedure commenced, topical anesthesia with $20 \%$ benzocaine gel (Topical paste, Produits Dentaires, Vevey, Switzerland) was used, which might

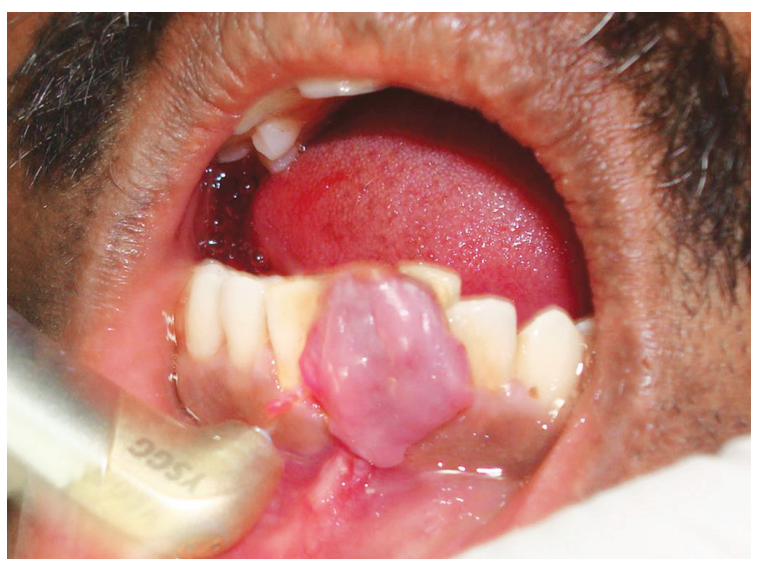

Fig. 2: Excision of the lesion using the Er,Cr:YSGG laser

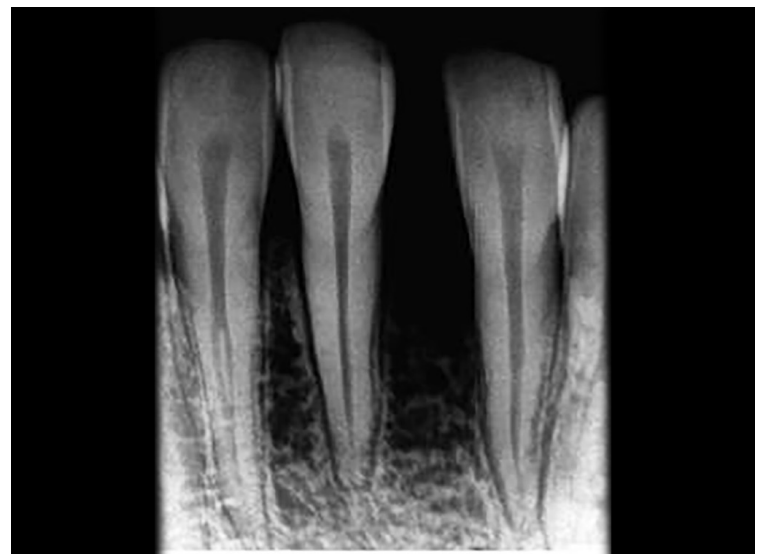

Fig. 4: Intraoral periapical radiograph showing interdental bone loss between the involved teeth

have been sufficient for carrying out the procedure but considering the patient being slightly apprehensive, an infiltration anesthesia was used wherein the surgical area was anesthetized using 2\% lidocaine with 1:80,000 adrenaline. The laser used in our present case report was erbium,chromium:yttrium-scandium-galliumgarnet (Er,Cr:YSGG) laser (Waterlase MD Turbo, Biolase Technology, California, USA). After proper eye protection was employed as suggested by the manufacturer, surgical excision of the growth was carried out with a glass tip (MZ5-500 $\mu \mathrm{m}$ diameter, length $6 \mathrm{~mm}$ ) and the laser settings used were $1.25 \mathrm{~W}, 8 \%$ water and $11 \%$ air in a contact mode. The excision proceeded from the periphery slowing dissecting the overgrowth under high-speed evacuation (Fig. 3).

Surgical area was not closed with sutures. All necessary postoperative instructions were elaborated in detail. Mild analgesics were prescribed and were advised to be taken only at patient's discretion. Home care was well augmented with the use of chlorhexidine rinses.

The excised lesion was stored in 10\% formalin and was sent for histopathologic examination (Fig. 4). H\&E section showing surface stratified squamous orthokeratinized epithelium with a delicate stromal component. The stroma shows admixed chromic inflammatory 


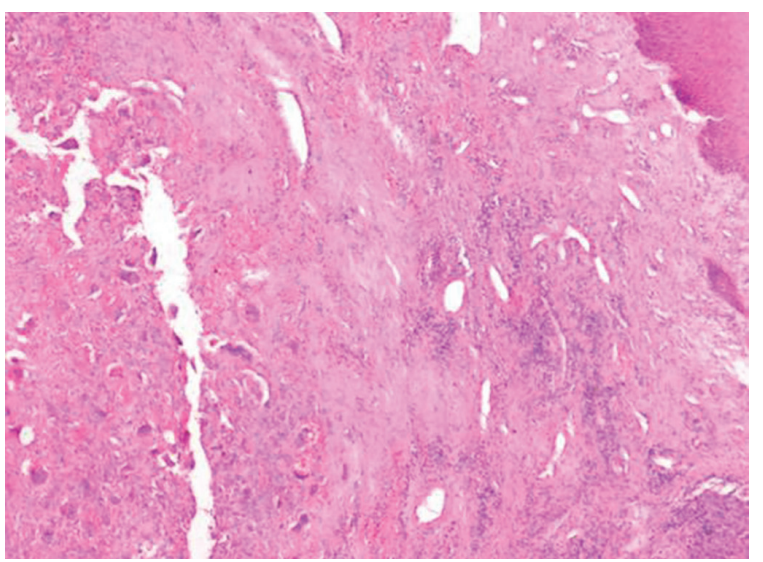

Fig. 5: H\&E section showing basal third of surface epithelium and numerous giant cells along with blood vessels seen scattered all over the connective tissue $(4 x)$

component with predominance of large numbers of numerous giant cells scattered all over the connective tissue. Most of the giant cells were in close proximity with plump proliferating blood vessels seen. No evidence of bone spicules were seen (Fig. 5). The above features are suggestive of PGCG. The healing was uneventful and the 6 months follow-up showed no recurrence (Fig. 6).

\section{DISCUSSION}

Peripheral giant cell granuloma is the least commonly diagnosed lesion among the various hyperplastic gingival lesions. ${ }^{4}$ It accounts for 5.1 to $43.6 \%$ of reactive gingival overgrowths. ${ }^{9}$ However, it is a common giant cell lesion found in the oral cavity. Peripheral giant cell granuloma is an extraosseous nodule composed of a proliferation of mononuclear and multinucleated giant cells in conjunction with prominent vascularity frequently found on gingiva or alveolar ridge. Multinucleated giant cells represent a reaction to unknown stimuli from the stroma component of PGCG. ${ }^{9}$ The origin of the multinucleated giant cells is an ever ending debate. One school of thought assumes them to show immunohistochemical features of osteoclasts, ${ }^{10,11}$ although they generally do not carry out the classic resorptive functions. Few suggest that they originate from the proliferating giant cells involved in resorption of deciduous teeth. Support for the origin of giant cells is from the endothelial cells of capillaries, which is favored by the fact that they are closely associated with blood vessels and vascular channels. A recent study by electron microscope suggested that these cells are highly specialized form of osteoclasts with a slight functional modification making them less resorptive than their counterparts. The giant cells thus represented various stages of differentiating osteoprogenitor cells. ${ }^{13}$

Peripheral giant cell granuloma is more common than CGCG with a peripheral to central ratio of 3 to $4: 1{ }^{8}$ CGCG is histologically similar to PGCG; however, CGCG

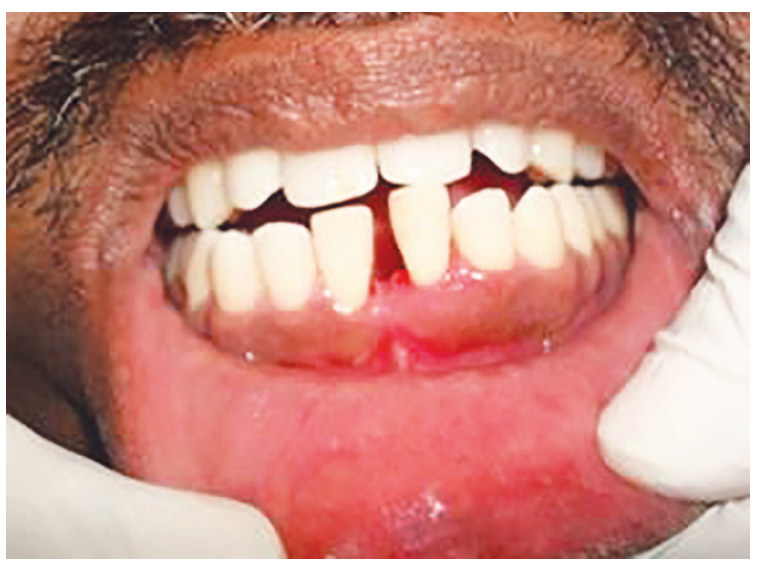

Fig. 6: Postoperative view after 6 months

represents frequent bone and tooth resorption. ${ }^{8}$ The histogenesis of PGCG and the nature of the lesion and the constituent cells remain controversial despite intense studies. A reactive nature of origin has been found in several immunohistochemical and ultrastructural studies. The mononuclear cells stain positive with histiocyte markers (lysozyme and alpha 1-antichymotrypsin) as well as show a positive reaction with CD-68, a macrophageassociated antigen. ${ }^{4,12}$ The presence of S- 100 positive cells which are evidence of Langerhans cells or their precursors, and the presence of fibroblasts, endothelial cells and myofibroblasts point toward a reactive nature of the PGCG ${ }^{4,14}$ An origin from periosteum rather than gingiva has been suggested since the lesion can cause superficial erosion of bone and occurs in edentate as well as dentate areas of the jaws. ${ }^{4}$ At present, it is generally agreed that PGCG is a reactive, non-neoplastic lesion formed by granuloma-like tissue dominated by multinucleated giant cells. ${ }^{15}$

There are no pathognomonic clinical features whereby these lesions can be differentiated from other forms of gingival hyperplasia, like pyogenic granuloma, fibrous epulis, peripheral ossifying fibroma, inflammatory fibrous hyperplasia, peripheral odontogenic fibroma, hemangioma cavernosum and papilloma. ${ }^{2,16}$ Thus in such cases, microscopic examination is mandatorily required for reaching a definitive diagnosis. Generally, this lesion is clinically indistinguishable from a pyogenic granuloma, although a PGCG is more likely to cause bone resorption than pyogenic granuloma, and the differences are otherwise minimal. ${ }^{4,16}$

Radiographic features are generally nonspecific. Occasionally, when the lesion occurs in the dentate area, they may cause superficial destruction of the alveolar margin or crest of the interdental bone when the granuloma is seen associated with the teeth. ${ }^{5}$ When the lesion occurs on edentulous ridge, it characteristically exhibits superficial 
erosion of the bone with peripheral 'cuffing' of the underlying bone. ${ }^{17}$ In our case, the intraoral periapical radiograph revealed the loss of crestal bone and periodontal ligament widening in the mandibular central incisors.

Very rarely, a PGCG is a manifestation of hyperparathyroidism, in which case changes in blood chemistry confirm the diagnosis. The most severe form of bone lesion in HPT is osteitis fibrosa cystica. However, the brown tumors of hyperparathyroidism are much more likely to be intraosseous in location and mimic a CGCG. ${ }^{18}$

Treatment consists of local surgical excision down to the underlying bone, for extensive clearing of the base which can be accomplished by conventional scalpels, electrocautery, radiosurgery or lasers. Although, radiosurgery and electrocautery have the ability to control bleeding, ensure greater visibility, and are less invasive than an incision, their use results in low tactile sensitivity for cutting, unavoidable burning flesh odor and poor postoperative healing. ${ }^{19}$ In addition to this lasers are blessed with the avoidance of needle infiltrated anesthesia which can be appreciated by many patients.

$\mathrm{CO}_{2}$, Nd:YAG, diode, helium-neon, and excimer are the various types of lasers that have been used for soft-tissue excision. They showed deleterious effects on tissues, such as carbonization, melting, and denaturation of proteins with consequent formation of toxic substances as well as compositional changes on the irradiated tissues. ${ }^{20}$ Ibarguren et al compared histologic biopsies excised by $\mathrm{Er}, \mathrm{Cr}$ :YSGG laser with $\mathrm{CO}_{2}$ and diode lasers and concluded that the histologic samples from the Er,Cr:YSGG laser at power settings of 1 to $2 \mathrm{~W}$ disclosed an apparently healthy tissue with minimal carbonization and charring that were tenfold less than in the diode or $\mathrm{CO}_{2}$ laser group. ${ }^{20}$

Erbium,chromium:yttrium-scandium-galliumgarnet laser has a greater affinity for hydrated tissue than nonhydrated tissue. It emits energy at a wavelength of $2,780 \mathrm{~nm}$ and delivers photons into an air water spray matrix, producing micro-explosive forces on water droplets. ${ }^{21}$ Higher water absorption coefficient cause rapid vaporization and micro-explosions and creates high pressure on the surrounding cells that blast off. ${ }^{22}$ Heat escapes by means of vaporization and ablation, causing minimum carbonization, which promotes tissue repair by a phenomenon known as photomodulation. ${ }^{23}$ It works at cellular levels in toxin reduction, accelerating lymphatic flow and increasing blood flow, thereby reducing pain. It enhances repair and induces regeneration by means of expression of collagen and elastic fibers during the early phase of wound healing. ${ }^{24}$

A recurrence rate of 5 to $70 \%$ has been reported. Recurrences are believed to be related to lack of inclusion of the periosteum or periodontal ligament in the excised specimen. ${ }^{4}$ The 6-month follow-up has shown no recurrence indicating that the given treatment along with maintenance of a good oral hygiene is sufficient to treat PGCG.

\section{CONCLUSION}

Peripheral giant cell granuloma is a rare reactive, softtissue exophytic mass of the oral cavity. This peculiar lesion is clinically indistinguishable from other hyperplastic gingival lesions. However, early and definitive diagnosis will enable conservative treatment with minimal damage to the adjacent hard tissues. The Er,Cr:YSGG laser works at cellular levels and promotes tissue repair by photomodulation. It induces regeneration during early stages of wound healing, resulting in little scar tissue formation with minimal need of local anesthesia and better patient compliance. Therefore, the Er,Cr:YSGG laser may be considered a patient and clinician-friendly tool.

\section{ACKNOWLEDGMENT}

The authors would like to acknowledge Dr Rajni Kanth, Oral Pathologist, for his valuable support and guidance.

\section{REFERENCES}

1. Falaschini S, et al. Peripheral giant cell granuloma: immunohistochemical analysis of different markers - study of three cases. Avances en Odontoestomatología 2007;23(4):189-196.

2. Chaparro Avendano AV, Berini Aytes L, Gay Escoda C. Peripheral giant cell granuloma: a report of five cases and Review of the literature. Med Oral Pathol Oral Cir Bucal 2005;10(1):48-57.

3. Cloutier, et al. An analysis of peripheral giant cell granuloma associated with dental implant treatment. Oral Surg Oral Med Oral Pathol Oral Radiol Endod 2007;103(5):618-622.

4. Sood S, Gulati A, Yadav R, Gupta S. Peripheral giant cell granuloma: a review. Ind J Multidisc Dentist 2012;2(2):435-440.

5. Adlakha, et al. Peripheral giant cell granul: a case report. J Ind Soc Pedod Preven Dent 2010;28(4):293-296.

6. Ghimire, et al. Peripheral giant cell granuloma: a case report. J Chitwan Med College 2013;3(3):28-30.

7. Sahingur SE, Cohen RE, Aguirre A. Esthetic management of peripheral giant cell granuloma. J Periodontal 2004;75(3): 487-492.

8. Motamedi, et al. Peripheral and central giant cell granulomas of the jaws: a demographic study. Oral Surg Oral Med Oral Pathol Oral Radiol Endod 2007;103(6):39-43.

9. Nedir R, Lombardi T, Samson J. Recurrent peripheral giant cell granuloma associated with cervical resorption. J Periodontol 1997;68(4):381-384.

10. Sapp JP. Ultrastructure and histiogenesis of peripheral giant cell granulomas of the jaws. Cancer 1972;30(4):1119-1129.

11. Lim L, Gibbins JR. Immunohistochemical and ultrastructural evidence of a modified microvasculature in the giant cell granulomas of the jaws. Oral Surg Oral Med Oral Pathol Oral Radiol Endod 1995;79(2):190-198. 
12. Regezi JA, Zarbo RJ, Lloyd RV. Muramidase, alpha-1 antitrypsin, alpha-1 antichymotrypsin and S-100 protein immunoreactivity in giant cell lesions. Cancer 1987;59(1):64-68.

13. Rajendran R. Benign and malignant tumors of the oral cavity. In: Shafer's textbook of oral pathology. Rajendran R, Sivapathasundaram B, editors Elsevier; 2012. p. 136-137.

14. Dayan D, Buchner A, David D. Myofibroblasts in peripheralgiant cell granuloma: light and electron microscopic study. Int J Oral Maxillofac Surg 1989;18(5):258-261.

15. Giansanti JS, Waldron CA. Peripheral giant cell granuloma: review of 720 cases. J Oral Surg 1969 Oct;27(10):787-791.

16. Moghe S, Gupta MK, Pillai A, Maheswari A. Peripheral giant cell granuloma: a case report and review of literature. People's Journal of Scientific Research 2013;6(2):55-59.

17. Agrawal A, Murari A, Singh A, Vutukuri S. Peripheral giant cell granuloma: a case report. Oral Maxillofac Pathol J 2013;4(2):408-412.

18. Choi, et al. Peripheral giant cell granuloma associated with hyperparathyroidism secondary to end stage renal disease: a case report. J Oral Maxillofac Surg 2008;66:1063-1066.
19. Arora S, et al. Treatment of tongue fibroma with Er, Cr: YSGG Laser. Clinical Advances in Periodontics 2014;4(1):25-30.

20. Ibarguren $C$, et al. Histologic evaluation of thermal damage produced on soft tissues by $\mathrm{CO}_{2}, \mathrm{Er}, \mathrm{Cr}$ : YSGG and diode lasers. Med Oral Pathol Oral Cir Bucal 2010;15(6): 912-918.

21. Boj JR, Hernandez M, Poirier C, Espasa E. Treatment of pyogenic granuloma with a laser-powered hydrokinetic system: case report. J Oral Laser Appl 2006;6:301-306.

22. Ishikawa I, Aoki A, Takasaki AA. Potential applications of erbium: YAG laser in periodontics. J Periodontal Res 2004; 39(4):275-285.

23. Tal H, Oegiesser D, Tal M. Gingival depigmentation by Er: YAG laser: clinical observations and patient responses. J Periodontol 2003;74(11):1660-1667.

24. Rosa DS, Aranha AC, Eduardo Cde P, Aoki A. Esthetic treatment of gingival melanin hyperpigmentation with Er:YAG laser-short-term clinical observations and patient follow-up. J Periodontol 2007;78(10):2018-2025. 